\title{
ASPECTOS DEL DISCURSO REPETIDO EN EL DIABLO COJUELO DE LUIS VÉLEZ DE GUEVARA
}

\author{
Dolores Azorín Fernández \\ Universidad de Alicante
}

Como observa Coseriu (1), las lenguas son ante todo técnicas históricas del discurso o del hablar. Una lengua se compone fundamentalmente de un conjunto de unidades léxicas y gramaticales, y de las reglas para su modificación y combinación en la oración; pero, además, una lengua almacena y transmite todo un caudal de elementos significativos que no pertenecen ya a la técnica del discurso, sino a lo que el mismo Coseriu bautiza con el nombre de discurso repetido; entendiendo por tal "...trozos de discurso ya hecho y que se pueden emplear de nuevo" (2).

Estas "expresiones hechas» se diferencian del resto de las frases construibles de un idioma, porque su significado no emana de la suma

(1) Eugenio Coseriu, «Introducción al estudio estructural del léxico» en Principios de semántica estructural, Madrid, Gredos, 1977, (Estudios y Ensayos, 259), pág. 113.

(2) /bid.s Pág. 113. 
de los significados parciales de los elementos que la integran, sino que son «...expresiones que se aprenden como conjuntos inanalizables y que los hablantes nativos emplean en ocasiones determinadas) (3).

Tomemos, por ejemplo, las siguientes expresiones del castellano:

\section{Pedir peras al olmo:}

(DRAE: s.v. PERA) que se usa para explicar que en vano se esperaría de uno lo que naturalmente no puede provenir de su educación, de su carácter o de su conducta.

Echar un capote: (DRAE, s.v. CAPOTE) Terciar en una conversación o disputa para desviar su curso o evitar un conflicto entre dos o más personas.

Andar uno de capa caída: (DRAE, s.v. CAPA) Padecer gran decadencia en sus bienes, fortuna y salud.

Estos tres ejemplos, tomados al azar entre los innumerables que se podían haber aducido, figuran en el DRAE como «frases figuradas y familiares", y resulta obvio que el valor que tienen para el hablante medio del castellano actual no se desprende de la combinación en la frase de sus constituyentes léxicos. Se trata -en palabras de Greimas- de formas connotadas, como en el caso de los proverbios:

Entendemos por connotación el traslado del significado del lugar semántico en que se sitúa, en función de su significante, a otro lugar.

Los proverbios son elementos connotados. En el caso de "Bonjour lunettes, adieu fillettes», el significado no se sitúa a la altura de la significación de lunettes (gafas) o de fillettes (chiquillas); el sentido del proverbio se encuentran en el plano en que se desenvuelven las consideraciones sobre la juventud y la vejez (4).

Además de las características que acabamos de examinar -es decir, no pertenecer a la técnica libre y situarse en el nivel de los elementos connotados-, el discurso repetido es también, por definición, inalterable. Esto es, que sus manifestaciones son asumidas por los hablantes como piezas que deben reproducirse en sus propios términos, sin que

(3) J. Lyons, Introducción en la lingüistica teórica, Barcelona, Teide, 1979, pág. 182. 357.

(4) Greimas, En torno al sentido. Ensayos de semiótica, Madrid, Fragua, 1973, pág. 
les sea dado introducir modificación alguna; de ahí que en algunas de sus variedades - especialmente los refranes y frases proverbialesaparezcan ciertos recursos como el ritmo, la rima, etc. que, al igual que en la poesía, tienen como fin el asegurar la memorización del texto (5).

Basándose en el principio de la inalterabilidad de sus términos, el profesor Lázaro Carreter acuña la expesión de Lenguaje literal, para todo discurso que haya sido cifrado con la pretensión de que perdure en su forma original. A él pertenece, con pleno derecho, toda esa

Multitud de manifestaciones que se integran en la competencia de los hablantes: plegarias, saludos, jaculatorias, eslóganes, conjuros, consignas, textos publicitarios, etc. [...] locuciones, frases hechas, modismos o idiomatismos, que recibimos y reproducimos como entidades acuñadas, sin que las hayamos forjado ni podamos introducir en ellas ninguna modificación. (6)

La noción de Lenguaje literal, (7) tal como la expone el profesor Lázaro, recubre y sobrepasa el concepto Cosereano de Discurso repetido, del que partimos en un principio. Así, mientras que para Coseriu el Discurso repetido estaría constituido por esos trozos de lenguaje ya hecho, ya hablado, transmitidos por la tradición lingüística y englobados en la competencia idiomática de los hablantes; el lenguaje literal - definido fundamentalmente por el carácter inalterable de sus términos-, comprendería todas aquellas manifestaciones lingüísticas - orales y escritas, literarias y no literarias, englobadas en la competencia de los hablantes o no- cifradas con el propósito de ser reproducidas literalmente y conservadas en sus propios términos.

(5) Samuel R. Levin distingue el lenguaje poético del ordinario, precisamente por la capacidad de aquél para perdurar en la memoria del lector: «En la poesía, tanto la forma como la impresión permanecen en la mente del lector. En otras palabras, el mensaje poético goza de una permanencia de que carece el mensaje ordinario. Entendemos por permanencia, no el hecho de que un poema determinado sobreviva generación tras generación y siglo tras siglo (permanencia general), sino el hecho de que el poema posee la facultad de permanecer en la mente del lector. Es decir, nos referimos aquí a su capacidad de ser fácilmente recordable». S.R. Levin, Estructuras lingüisticas en le poesía, Madrid, Cátedra, 1977 , pág. 89.

(6) F. Lázaro Carreter, "La lengua de los refranes" en Estudios de lingülstica, Madrid, Ed. Crítica, 1980, pág. 223.

(7) "Llamamos Lenguaje litera/ al empleado en comunicaciones que deben ser descifradas en sus propios términos y que asi deben conservarse». F. Lázaro Carreter, «El mensaje literal» en Estudios de lingüistica, op. cit., pág. 160. 
A modo de resumen provisional, podemos concluir que el llamado discurso repetido y ciertas formas del lenguaje literal, se caracterizan frente al lenguaje ordinario:

a) Por su calidad de trozos hechos, de lenguaje ya hablado.

b) Por no ser deducible su significado a partir de la mera suma constructiva de las unidades léxicas que lo integran. Es decir, por su carácter de elementos connotados.

c) Por estar destinado a ser reproducido literalmente.

Estas secuencias de lenguaje ya hablado no constituyen un bloque unitario, sino que recubren una amplia gama de variedades, de límites poco precisos las más de las veces, que difícilmente se sujetan a clasificaciones exactas y sin residuos.

Eugenio Coseriu, partiendo de los presupuestos de la lexicología estructural, distingue tres grandes grupos de unidades dentro del discurso repetido, atendiendo a su conmutabilidad y equivalencia con otras tantas unidades de distintos planos pertenecientes a la técnica libre del discurso:

Precisamente, nos parece que habría que distinguir tres tipos, a los que podemos llamar, provisionalmente, «equivalentes de oraciones», "equivalentes de sintagmas» $y$ «equivalentes de palabras». (8)

Dentro del primer grupo habría que incluir, por supuesto, todo el bagaje paremiológico «englobado y transmitido» por la tradición lingüística: proverbios, sentencias, refranes, «wellerismos», dialogismos, frases proverbiales, etc. que constituyen verdaderas citas, dotadas de una curva entonativa peculiar con lo que subrayan, también en el plano fónico, su independencia textual respecto del discurso en que se insertan, no diferenciándose en nada de las citas literarias; de ahí que Coseriu reconozca en los refranes una forma de literatura (9), y que el profesor Lázaro prefiera «...definir los refranes como lo que son: manifestaciones folklóricas del discurso repetido - yo prefiero llamarlo

(8) E. Coseriu, op. cit., pág. 115.

(9) Cfr. Ibid. 
«lenguaje literal»-, incorporadas a la competencia de los hablantes que forman una misma comunidad idiomática» (10).

Expresiones como "De noche, todos los gatos son pardos» o "Más vale pájaro en mano que ciento volando", son verdaderas citas literarias (11). J. Casares, utilizando argumentos similares a los hasta aquí expuestos, rechaza de plano la inclusión de los refranes en el diccionario, porque para él «...el refrán no es un hecho expresivo reducible a una equivalencia conceptual unitaria [...] Es [...]. una frase completa o cláusula independiente, en la que se relacionan por lo menos dos ideas" (12).

Existen otras unidades del discurso repetido, no ya conmutables en el terreno de los textos o de las oraciones, sino que se presentan como equivalentes de sintagmas. Se han empleado diversas etiquetas para referirse a estas combinacones estables, tales como: sintagmas estereotipados (Coseriu), sintemas (Martinet), lexías complejas (Pottier), etc. Acuñaciones tales como: "Sin ton ni son» (= sin fundamento, sin razón) o "A trancas y a barrancas» ( = pasando sobre todos los obstáculos, con grandes dificultades), entrarian a formar parte de este grupo.

Por último, habría que contar con aquellas expresiones pluriverbales estables reemplazables por palabras:

Hacer alarde, echar en cara, hacer hincapié, pueden ser reemplazados por alardear, reprochar, insistir, etc. Estas unidades funcionan como lexemas $y$, por lo tanto, su estudio pertenece a la lexicología. (13)

Esta sencilla clasificación se complica extremadamente cuando descendemos al detalle y nos topamos con los especímenes de esas tres grandes clases de unidades que acabamos de examinar. Este es el problema con que ha de enfrentarse la lexicografia, disciplina que ha de

(10) F. Lázaro Carreter, "Literatura y folklore: los refranes», en Estudios de lingüistica, op. cit., pág. 208-9.

(11) Coseriu propone el nombre de textemas para estas unidades del discurso repetido, pero observa que su estudio escapariá del ámbito de la lexicología. La misma opinión manifiesta B. Pottier con respecto a estos elementos, que él llama lexías textuales. (Cfr. B. Pottier, Gramática del espeñol, Madrid, Alcalá, 1971, pág. 26).

(12) J. Casares., Introducción a la lexicografla moderna, Madrid, Consejo Superior de Investigaciones Científicas, 1969, Revista de Filología Española, Anejo LIII, págs. 198-199.

(13) Coseriu, Op. cit. pág. 117. 
trabajar con dichos especímenes, recogiéndolos $y$, posteriormente, asignándoles un lugar en el diccionario acorde con el status lingüístico que les corresponde y que previamente ha de otorgárseles. De este problema se ocupó ampliamente D. Julio Casares en su Introducción a la lexicografia moderna, en un intento de subsanar el caótico tratamiento que el diccionario académico otorga a este tipo de unidades. Su clasificación de las locuciones, la diferenciación que establece entre la frase proverbial y el refrán, así como su intento de definición del modismo, constituyen una verdadera teoría -0 , al menos, interesante aproximación - del llamado discurso repetido (14).

Pero no es nuestro objetivo teorizar sobre el lenguaje literal, sino únicamente deslindar, al menos someramente, estos productos insertos en la tradición lingüística de todo lo que en ella es técnica pura del hablar, asi como el esbozo de una amplia clasificación de los mismos. Nuestro principal interés radica en el tratamiento sui generis, que Vélez de Guevara otorga a estas fórmulas en El diablo cojuelo; esquemas patrimoniales del saber lingüístico, muchos de los cuales, como los refranes, se incorporan al caudal léxico de nuestro autor con las huellas visibles de un desgaste prolongado en la literatura.

Al estilo de Vélez, en esta su única obra en prosa, no se le han escatimado calificativos tendentes a ponderar la atrevida soltura con que maneja el idioma; todos cuantos se han ocupado de esta obrita hacen hincapié en la desenvoltura del ecijano para usar del juego de palabras, para la construcción de la metáfora inesperada, para el recurso al equivoco, etc. Así se expresaba Bonilla - por citar a uno de los primeros estudiosos de El diablo Cojuelo - en el prólogo a su edición de 1910:

Vélez de Guevara como Quevedo es un escolástico del idioma. No hay que perder una sola de sus palabras, no hay que confiar en el valor directo de cualquiera de sus frases, porque lo mejor del cuento pasaría quizás inadvertido. Es preciso estar siempre ojo avizor para saborear como es debido aquellas atrevidas metáforas, aquellas extravagantes relaciones, aquellos estupendos equívocos, aquellas arbitrarias licencias con que se complace [...] sólo el muy familiarizado con los secretos del habla podría darse cabal cuenta de las bellezas de una obra semejante (15).

(14) J. Casares, Op. cit. especialmente las páginas comprendidas entre la 167 y la 242.

(15) A. Bonilla, "Prólogo», en Luis Vélez de Guevara, El Diablo Cojuelo, Madrid, Bibliófilos Madrileños, 1910, Pág. XXX. 
Entre las arbitrarias licencias que Vélez de Guevara se permite, en ese afán por rizar el rizo de lo imposible en el uso artístico del lenguaje, se encuentra lo que Muñoz Cortés denominó «rotura de las formas», que siendo una constante general del Barroco $-y$ no sólo en el terreno literario - adquiere en Luis Vélez una modulación más, otra vuelta de tuerca, al atreverse a jugar con esas piezas de estructura monolítica, intocables por definición, que forman parte del discurso literal o repetido, en las distintas modalidades de su manifestación.

Ese rompimiento de las formas lo sitúa el profesor Muñoz en tres niveles distintos:

a) Rotura de la unidad estructural fonética: «...que son demonias hembras»; "restatuas gigantas», etc.

b) Rotura de la unidad funcional. Conversión de sustantivos en adjetivos: "enamorado murciélago», "caballero huracán», etc.

c) Rotura de la unidad de sentido. (16).

Dentro de este último apartado, se considera que ha habido rotura de la unidad de sentido, cuando se opera cualquier modificación, bien en el plano del significante, bien en el del significado, en cualquier unidad del discurso no importa cuál sea su extensión. De manera que la rotura del sentido puede afectar no sólo a la palabra, sino también a esas otras unidades complejas, de estructura pluriverbal que constituyen el discurso repetido.

Así, por ejemplo, hay rotura del significado en el nivel mínimo - el de la palabra o lexía simple - , cuando Vélez utiliza el término familiar (17) en su doble acepción de:

a) 'espíritu familiar y doméstico con quien tiene trato alguna persona'

(16) M. Muñoz Cortés, «Aspectos estilísticos de Vélez de Guevara en El Diablo Cojuelo», R.F.E., XXVII, (1943), pág. 67.

(17) Covarrubias, s.v. familiar - además del significado principal del vocablo: 'el allegado a casa' - distingue nítidamente ambas acepciones: ufamiliares, los Ministros del Santo Oficio de la inquisición, que no son oficiales delia, pero llamándolos acuden a las cosas que se les mandan y encomiendan. También llaman familiares a los demonios que tienen trato con alguna persona...) (Covarrubias, Tesoro de la lengua castellana o española, Madrid, Turner, 1979). 
b) 'cierto colaborador del tribunal de la Inquisición' en el siguiente pasaje de El diablo Cojuelo:

- « Quién diablos suspira aquí? [...]

- Yo soy, señor Licenciado, que estoy en esta redoma, adonde me tiene preso ese astrólogo [...]

- Luego, familiar eres - dijo el Estudiante-.

- Harto me holgara yo - respondieron de la redoma - que entrara uno de la Santa Inquisición..." (18).

Dentro del ámbito del discurso repetido, asistimos a la reproducción del mismo fenómeno de rotura de la unidad de sentido, ante el empleo contrahecho de una locución - verbal en este caso, según la clasificación de Casares - : «dar gato por demonio», reconstruída sobre el conocido modelo de "Dar gato por liebre», que Vélez pone en funcionamiento en el pasaje que sigue:

- «l...] nunca he estado más sin reputación que ahora en poder deste vinagre, a quien por trato me entregaron mis propios compañeros, porque los traía al retorterova todos [...] y a cada momento, a los más agudos les daba gato por demonio» (pág. 25).

Con la misma soltura son manipulados los refranes y frases proverbiales; no faltan ejemplos ilustrativos de rotura y recomposición de estas piezas:

- "Camino del infierno tanto anda el cojo como el viento», contrapartida amañada del conocido: "Camino de Santiago, por donde anda tanto el cojo como el sano». (pág. 25)

- «Siempre quiebra la soga por lo más forastero», que modifica el también popular: «Siempre quiebra la soga por lo más delgado» (pág. 114)

- «Al fin de los años mil, vuelven los nombres por donde solían ir»; versión acomodada de «Al fin de los años mil, vuelven las aguas por donde solian ir». (pág. 56)

(18) Luis Vélez de Guevara, El Diablo Cojuelo, ed. de F. Rodriguez Marín, Madrid, España-Calpe, 1918, (Clásicos Castellanos, 38) pág. 19. Todas las citas que, de ahora en adelante, aparezcan en nuestro trabajo, pertenecen a esta misma edición; por lo que, a partir de aquí. me limito a consignar la página tras cada cita textual del Cojuelo. 
Locuciones, refranes y también ciertas fórmulas, más o menos lexicalizadas, procedentes del lenguaje religioso sufren el mismo tratamiento distorsionador: (pág. 6)

- «El diablo cojuelo nace a la luz concebido sin teatro original».

- «Diluvio en pena» por «alma en pena» (pág. 40).

- «Ir al infierno en coche y alma» por "en cuerpo y alma» (pág. 42)

- «lte, río es» por «lte, missa est». (pág. 4)

Ante estos hechos que acabamos de exponer, cabe preguntarse hasta qué punto se puede considerar a Vélez de Guevara como un innovador en el empleo de las fórmulas fijas del discurso repetido, de todo ese bagaje de piezas literales que durante varios siglos - sobre todo en lo que respecta al caudal paremiológico - han sido cantera para el adorno del discurso literario. Así lo declara Juan de Mal Lara, parafraseando a Erasmo, cuando afirma que:

Los refranes aprovechan para el ornato de nuestra lengua $y$ escriptura, son como piedras preciosas salteadas en las ropas de gran precio, que arrebatan los ojos con sus lumbres, y la disposición da a los oyentes gran contento. (19)

En el caso concreto del uso literario del refrán, podemos hallar ejemplos de alteración consciente de su estructura que se remontan al S. XIV; como sucede en el Tractado de la doctrina de Pedro de Beragüe, donde el autor altera esta modalidad de lenguaje literal con fines estilísticos:

[...] el más sorprendente de los primitivos artistas de refranes [Pedro de Beragüe]: tan sorprendente, que no tiene competidores durante casi un siglo. Hay en el Tractado tres ejemplos de manipulación estilística de los refranes dificilmente sobrepujados por ninguno de los expertos posteriores. (20).

(19) Juan de Mal Lara, Filosoffa vulgar, t. I, Barcelona, Selecciones Bibliográficas, 1958-59, pág. 91.

(20) Eleanor S. O'Kane, Refranes españoles medievales, Madrid, Anejos del Boletín de la Real Academia Española, 1959, pág. 21. 
Los ejemplos que transcribe Eleanor S. O'Kane muestran el modo magistral con que Beragüe sabe apropiarse del espiritu del refrán en cuestión para ilustrar su propia opinión, pasando por alto el respeto a la letra, a la literalidad, esencial en el empleo de estas pequeñas piezas de la sabiduría popular. Así, en el incipit de la obra: «[...] el autor explica el propósito que le mueve a escribir su tratado»:

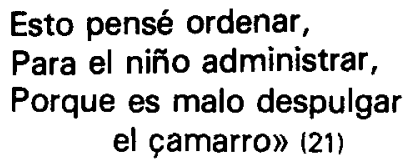

En el Seniloqium se encuentra el proverbio al que alude Beragüe en la estrofa citada: «Home viejo de castigar y pellón prieto de espulgar, malo es) (22)

En el S. XIV no hay más ejemplos conocidos del empleo estilizado del refrán hasta llegar a la técnica de Alfonso Alvarez Villasandino, que consiste en la desmembración del mismo para la posterior incorporación al texto de sus elementos:

«He aquí algunos pasajes que ilustran su técnica especial:
E vedes amigo, que desto $m^{\prime}$ encelo,
E por su venida mi barba repelo.
Echad en remojo esa que rapades"). (23)

Tres versos en que se diluye el conocido refrán: 'Cuando las barbas de tu vecino vieres pelar, pon la tuya en remojo'.

Pero ni en este caso ni en Beragüe podemos decir que exista rotura del sentido como sucede en el procedimiento de Vélez. Tampoco en las manipulaciones a que se verá sometido el refrán tanto en El Corbacho como en La Celestina, se da una cosa semejante; se dará, eso sí, la apropiación del meollo sentencioso del dicho popular, actitud que Jules Piccus pone en relación con el rechazo por parte de la literatura caballe-

(21) /bid. pág. 21.

(22) Cfr. Seniloquim (1450-1500), Bibl. Nac., M.S. 19.343; (ed. por F. Navarro Santín, en Revista de Archivos Bibliotecas y Museos, t. X, 1904).

(23) E.S. O'Kane, Op. Cit., pág. 22. 
resca y clerical de la Edad Media de los ejemplos y de las sentencias populares, por considerarlos demasiado "llanos et declarados" y sólo aptos para los «non muy letrados ni muy sabidores» - según manifiesta D. Juan Manuel- (24). Idéntica opinión expresa Combet, cuando se refiere al «vieux mépris manifesté envers le proverbe vulgaire par la litterature médievale aristocratique et clericale. Mépris qui acompagne les premiers pas de la litterature castillane». (25)

Pero no creemos que sea ésta la motivación que lleve al de Talavera, en El Corbacho, y a Rojas en la Tragicomedia a modificar la linealidad del refrán cuando incurren en ello. M. Bataillon no parece conceder mayor trascendencia a las licencias que, en este sentido se toma Rojas, que el de favorecer un mejor acoplamiento de lo ya hecho, el refrán, a su propio discurso; lo cual prueba, no obstante, que el contenido del refrán seguía primando sobre la forma:

Rojas semble avoir été plus sensible au contenu des proverbes qu'à leur forme fixée, ou peut-être a-t-il trouvé plaisant de varier à l'occasion cette forme pour mieux adapter le «tout fait» au propos personnel. (26).

La valoración y el aprecio que el movimiento humanista dispensó a las formas tradicionales de la sabiduría popular - refranes, proverbios, dichos sentenciosos, etc-, fue el paso decisivo para la dignificación de la forma de los refranes, puesto que su contenido, ya desde $D$. Juan Manuel, era admitido sin reservas:

Intention morale donc [...] Mais aussi qualité artistique; car le proverbe, pour séduire et être admis par l'usage linguistique, doit aussi être consideré comme un ornement du discours. (27)

El erasmismo «aportó un refuerzo [...] a la tradición española de los proverbios", (28) sobre todo por lo que respecta al aprecio por la forma de los refranes y la estimación de sus cualidades artísticas; hasta el pun-

(24) Cfr. J. Piccus, "Refranes y frases proverbiales en el Libro del Cavallero Zifar», N.R.F.H., XVIII, Núms 1 y 2, pág. 5.

(25) Combet Recherches sur le "Refranero» castillan, Paris, Les Belles Lettres, 1971, pág. 95.

(26) M. Batillon, "La Celestine» selon Fernando de Rojas, Paris, Didier, 1961, pág. 98.

(27) Combet, Op. cit., pág. 91.

(28) M. Bataillon, Erasmo y España, México, Fondo de Cultura Económica, 1950, pág. 626. 
to de que Juan de Valdés - como es sobradamente conocido-, utilice los refranes castellanos como ejemplos del buen decir, elevándolos a la categoria de autoridades del idioma: «...en aquellos refranes se vee mucho bien la puridad de la lengua castellana» (29); dirá Pacheco, en un pasaje del Diálogo de la lengua.

En el s. XVIl concurren, en mi opinión, dos factores que van a propiciar ese tratamiento sui generis, iconoclasta y - ¿por qué no? - también lúdico y desenfadado de que hace alarde Vélez en El cojuelo, y que alcanza no sólo a los refranes, sino también a otras modalidades del discurso repetido.

A lo largo de esta centuria se empieza a fraguar toda una tendencia crítica y revisionista que hace hincapié no en la cobertura externa del refrán, sino en su contenido, poniendo en tela de juicio el caracter infalible de la doctrina que encierran:

[...] a partir du XVII ${ }^{e}$, se fait jour une tendance toute différente sinon opposée: le proverbe se trouve alors mis en question en tant que porteur de valeurs morales ou même pratiques. (30).

Tendencia que se manifiesta ya plenamente en Gracián en su «Critica reforma de los comunes refranes», (31) y que culminará, en el siglo siguiente, en Feijoo. También Quevedo la asume, por vía de la sátira, en su Cuento de cuentos (32) donde la crítica se extiende también a otras modalidades del discurso repetido (locuciones, modismo, etc.)

En segundo lugar, además de la puesta en cuestión de las verdades atesoradas en nuestro refranero, cabe también pensar en el agotamiento del mismo como recurso estilístico; dificultad que, por ejemplo, Lope de Vega salvará en La Dorotea recurriendo al empleo de refranes poco frecuentes que, por su misma oscuridad, podían seguir ofreciendo cierto atractivo:

(29) Juan de Valdés, Dialogo de la lengua, ed. de A. Comas, Barcelona, Bruguera, 1972, pág. 75.

(30) Combet, Op. cit., pág. 93.

(31) Baltasar Gracián, El criticón, vol. III, ed. y notas de E. Correa Calderón, Madrid, Espasa-Calpe, 1971, (Clásicos Castellanos, 167) págs. 162-169.

(32) F. de Quevedo, "Cuento de Cuentos" en Obras satíricas y festivas, ed. y notas de José M* Salaverría, Madrid, Espasa-Calpe, 1975, (Clásicos Castellanos, 56), págs. 166186. 
In La Dorotea, Lope faced the apparently insurmountable difficulty of using proverbs, crystallized and inflexible, with originality, after Fernado de Roxas and Cervantes had seemingly exhausted their possibilities. His solution was to glean some scores of refranes hitherto unexploited, often obscure in meaning and further obscured in application. (33)

Vélez, en el recurso al refrán contrahecho y a la manipulación de las locuciones y de los clichés del lenguaje religioso, se inscribe dentro de esa misma tendencia de búsqueda de la novedad, en este caso, mediante el «reciclaje» lingüístico del tópico.

(33) Edwin S. Morby, "Proverbs in La Dorotea», Romance Philology, VIII, (1954-55), pág. 251. 